\title{
Validation and Quantification of Domperidone in Spiked Plasma Matrix Using Reversed Phase HPLC-UV Method
}

\author{
Sekar Ayu Pawestri ${ }^{1}$, Akhmad Kharis Nugroho ${ }^{1^{*}}$, Endang Lukitaningsih ${ }^{2}$, and Purwantiningsih \\ Purwantiningsih ${ }^{3}$ \\ ${ }^{1}$ Department of Pharmaceutics, Faculty of Pharmacy, Universitas Gadjah Mada, Yogyakarta 55281, Indonesia \\ ${ }^{2}$ Department of Pharmaceutical Chemistry, Faculty of Pharmacy, Universitas Gadjah Mada, Yogyakarta 55281, Indonesia \\ ${ }^{3}$ Department of Pharmacology and Clinical Pharmacy, Faculty of Pharmacy, Universitas Gadjah Mada, \\ Yogyakarta 55281, Indonesia
}

\section{* Corresponding author:}

tel: $+62-82136106565$

email:a.k.nugroho@ugm.ac.id

Received: February 22, 2021

Accepted: May 3, 2021

DOI: $10.22146 /$ ijc.64253

\begin{abstract}
Pharmacokinetics studies of domperidone generally analyze plasma matrix samples. The present work aimed to develop and validate a rapid and simple reversed phase-HPLC method for quantifying domperidone in plasma matrices. The chromatographic method implemented: 1. Luna Phenomenex ${ }^{\circledast} \mathrm{C18}(250 \mathrm{~mm} \times 4.6 \mathrm{~mm}$ i.d; $5 \mu \mathrm{m})$ column, 2. isocratic mobile phase mixture of phosphate buffer 0.02 M:acetonitrile $(70: 30, v / v)$ with a flow rate of $1 \mathrm{~mL} / \mathrm{min}, 3$. UV detection at $285 \mathrm{~nm}$. Domperidone and propranolol hydrochloride (as internal standard) were extracted from the deproteinated plasma sample. The method linearity was 0.998 in the range concentration of 15-200 $\mathrm{ng} / \mathrm{mL}$. The percentage of accuracy error was between -8.49$4.31 \%$, while the percentage coefficient variation of precision ranged between 5.11$14.24 \%$. This proposed method was simple, rapid (separation time less than $10 \mathrm{~min}$ ), and selective. The validation parameters responses satisfied the method's requirements to determine domperidone in a plasma sample.
\end{abstract}

Keywords: domperidone; RP-HPLC; spiked plasma; validation

\section{- INTRODUCTION}

Domperidone, a dopamine antagonist, is commonly prescribed as an antiemetic and prokinetic agent for the treatment of nausea and vomiting. The recommended daily dose is $10-40 \mathrm{mg}$ in divided doses. Domperidone has a low oral bioavailability, approximately $13-17 \%$, due to the extensive first-pass effect and efflux by transporters in the small intestine [1-3]. Therefore, the modification or utility of advanced technology of formulation for improving the delivery system of domperidone is demanded. The improvements facilitate an efficient in vivo evaluation, such as in pharmacokinetics and bioequivalence studies. The validation method for domperidone analyses in biological samples, i.e., plasma, is crucial for providing reliable data.

There are several reports exhibit various methods for quantifying domperidone in plasma matrices. The methods implement a high liquid chromatography approach coupled with UV (HPLC-UV), fluorescence, or tandem mass spectrometry (HPLC-MS/MS) detection [2-12]. Other reports applied the ultra-performance liquid chromatography-tandem mass spectrometry (UPLCMS/MS) [13-14] and the ultra-fast liquid chromatography (UFLC) method with fluorescence detection [15]. Some reports show a better selectivity and sensitivity of drug quantification. However, the procedure uses extraction with chloroform, a relatively toxic solvent reported with hepatotoxicity and nephrotoxicity risks $[4,16]$. In addition, the sample extraction needs a freezing process which is time-consuming [6]. The solid-phase extraction method was also investigated to extract samples in the plasma but require long steps in preparation [7]. Another method showed a relatively long separation time of about $12 \min$ [3]. 
The study's objective was to develop a rapid and simple HPLC-UV method to quantify domperidone in plasma, along with a very simple extraction in sample preparation and faster run time analysis. The method could be the reference method for pharmacokinetic studies.

\section{- EXPERIMENTAL SECTION}

\section{Materials}

The materials used were domperidone (EDQM, France), propranolol $\mathrm{HCl}$ (Sigma-Aldrich, USA), methanol and acetonitrile HPLC grade (E-Merck, Germany), potassium dihydrogen phosphate (E-Merck, Germany), distilled water (PT. Ikapharmindo Putramas), orthophosphate acid 85\% (E-Merck, Germany), and blank human plasma that was obtained from the Indonesian Red Cross in Yogyakarta-Indonesia.

\section{Instrumentation}

High-Performance Liquid Chromatography (L2000 Hitachi, with L-2130 pump and Hitachi L-2420 UVVis detector), and $0.45 \mu \mathrm{m}$ syringe filter (Phenomenex ${ }^{\odot}$ ) were used.

\section{Procedure}

\section{Chromatographic conditions}

The LC system used chromatographic column Luna Phenomenex ${ }^{\otimes} \mathrm{C} 18(250 \mathrm{~mm} \times 4.6 \mathrm{~mm}$ i.d; $5 \mu \mathrm{m})$. The mobile phase was composed of an isocratic mixture of phosphate buffer $0.02 \mathrm{M}$ and acetonitrile (70:30, v/v) with a flow rate of $1 \mathrm{~mL} / \mathrm{min}$, while the injection volume was $20 \mu \mathrm{L}$, and $285 \mathrm{~nm}$ UV detection.

\section{Preparation of standard solutions}

The stock solution of $100 \mu \mathrm{g} / \mathrm{mL}$ of domperidone and propranolol $\mathrm{HCl}$ (as an internal standard) was separately prepared in methanol. The domperidone stock solutions were diluted with methanol to obtain various concentrations in the range of $0.75-10.00 \mu \mathrm{g} / \mathrm{mL}$ (as working solutions).

\section{Sample preparation}

Sample plasma was prepared by spiking domperidone and propranolol $\mathrm{HCl}$ standard solutions. An aliquot of $200 \mu \mathrm{L}$ of blank plasma was spiked with an appropriate concentration of domperidone working solutions to obtain range calibration standards concentrations $(15-200 \mathrm{ng} / \mathrm{mL})$, while the final concentration of propranolol $\mathrm{HCl}$ was $1 \mu \mathrm{g} / \mathrm{mL}$. Then the plasma was deproteinated with the addition of $600 \mu \mathrm{L}$ of acetonitrile. The mixture was shaken for $2 \mathrm{~min}$ and centrifuged at $10.000 \mathrm{rpm} 4{ }^{\circ} \mathrm{C}$ for $10 \mathrm{~min}$. The supernatant was taken and put in the vial. Acetonitrile was added again to precipitate the protein, centrifuged such a condition again before. Then, the supernatant was separated and merged with the same sample vial. The supernatant was dried with heat airflow. Then the residue was added with $1 \mathrm{~mL}$ of the mobile phase. The solution was filtered using a membrane filter of $0.45 \mu \mathrm{m}$ before being injected into the HPLC system.

\section{System suitability}

This test was performed by injecting the analytes in plasma at a $200 \mathrm{ng} / \mathrm{mL}$ concentration six times into the HPLC systems. The chromatographic parameters were observed, such as peak area and retention time, by determining those percentage coefficients of variance (\% $\mathrm{CV}$ ), asymmetry, resolution, and height equivalent to the theoretical plate (HETP) [17].

\section{Validation parameters}

The validation method was according to standard guidelines [18] in terms of selectivity, linearity, lower limit of quantification (LLOQ), accuracy, and precision.

Selectivity. The selectivity was analyzed by comparing the blank samples and spiked samples chromatograms. The interference chromatograms around the retention times of domperidone and propranolol $\mathrm{HCl}$ were observed. The complete separation of the peak of blank plasma samples, analyte, and internal standard was also evaluated.

Linearity. Determination of linearity of the method was performed by spiking the working standard solutions to the blank plasma. The linearity was evaluated by constructing calibration curves in the range of 15$200 \mathrm{ng} / \mathrm{mL}$ for domperidone. Propranolol $\mathrm{HCl}$ as an internal standard was added to each solution at a concentration of $1 \mu \mathrm{g} / \mathrm{mL}$. The ratio peak area of domperidone to the peak area of internal standard was plotted against their corresponding concentration. The 
linearity was assessed by calculating the correlation coefficient. The error percentage recovery of each concentration must be in the range of $\pm 20 \%$ for LLOQ and $\pm 15 \%$ for other concentrations.

Accuracy and precision. Accuracy and precision were conducted using four concentration levels: the LLOQ, low $(3 \times$ LLOQ), medium (around $30-50 \%$ of the range of calibration curves), and high ( $75 \%$ of the upper calibration curve range) levels. The concentration of domperidone used were $15,45,95$, and $150 \mathrm{ng} / \mathrm{mL}$ and propranolol $\mathrm{HCl}$ at $1 \mu \mathrm{g} / \mathrm{mL}$. Each of the concentration levels was prepared for five replications. Accuracy was determined by comparing the observed concentration to the nominal concentration expressed as a percentage of deviation or error from nominal concentration (\%-error). The acceptance criteria for accuracy were the $\%$ error of the mean of observed concentration within $15 \%$ of the nominal concentration, except for the LLOQ, which was $\leq 20 \%$ of the nominal concentration. The precision of the method was evaluated by calculating $\% \mathrm{CV}$. The acceptance criteria for precision was that the $\% \mathrm{CV}$ did not exceed $15 \%$ of the sample concentration and for LLOQ not exceed $20 \%$.

Lower limit of quantification (LLOQ). The lowest domperidone concentration can be quantified with acceptable accuracy and precision (\% CV < 20\%).

\section{- RESULTS AND DISCUSSION}

\section{Sample Preparation}

Determining the drug from the biological sample, such as plasma, requires an extraction step before injecting it into the liquid chromatography analysis system. Several extraction techniques are solid-phase extraction (SPE), liquid-liquid extraction (LLE), and protein precipitation [19-20]. Protein precipitation is the simple and fast techniques applied for extraction in which its supernatant could be directly injected into the system compare with SPE and LLE, which need a further step before being injected [20-21].

The use of the protein precipitation technique in this proposed method gave advantages, i.e., only using acetonitrile solvent to precipitate the protein plasma and also providing a shorter time in sample preparation as its simplicity.

\section{Development of Chromatographic Condition}

The ratio of the mobile phase (phosphate bufferacetonitrile) was optimized. It was noticed that increase acetonitrile composition in the mobile phase reduces the retention time also shorter resolution between domperidone and internal standard. The best ratio combination of mobile phase for this method was phosphate buffer:acetonitrile $(70: 30, \mathrm{v} / \mathrm{v})$ as exhibit a good peak shape, retention time, and resolution. Therefore, its ratio was selected for further analysis.

The $\mathrm{pH}$ of the mobile phase is also critical when analytes have acidic, basic, or both characteristics. The $\mathrm{pH}$ of the eluent should be controlled and could be achieved by using buffers. The $\mathrm{pH}$ affects the analyte's protonation state, which influences its interaction with the stationary and mobile phases [22]. On the orientation of choosing the $\mathrm{pH}$ of phosphate-buffered as a mobile phase, the value of $\mathrm{pH}$ used were 3,5 , and 8 . At the higher $\mathrm{pH}$, retention time was increased, and sensitivity was reduced for domperidone and propranolol $\mathrm{HCl}$. At higher $\mathrm{pH}(\mathrm{pH}>3)$, the presence of amine moieties in domperidone can interact with silanol residues of silica gel (C18) by electrostatic interaction resulting in peak tailing and increasing the retention time [23]. Meanwhile, at lower $\mathrm{pH}$ ( $\mathrm{pH}$ of 3), the retention time decreased, and the peak shape of both analytes was better. So, the best $\mathrm{pH}$ of phosphatebuffered chosen was at $\mathrm{pH} 3$.

The flow rate of the mobile phase affects the retention time and peak shape [24]. On the process development, the best result for the flow rate was $1 \mathrm{~mL} / \mathrm{min}$ as showed better retention time and resolution. Therefore, it was selected as the best flow rate condition for the method.

\section{Validation of the Method}

\section{System suitability}

The system suitability test was performed before running the quantitative analysis to ensure the instrument was in a good performance, so that gave the valid results. In this study, chromatographic parameters for the system suitability test were satisfied with system suitability criteria (Table 1 ). The $\% \mathrm{CV}$ of peak area and 
retention time was $<2$, asymmetry $\leq 2$, resolution $>2$, and HETP $>2000$. In addition, the separation time between domperidone and propranolol was less than $10 \mathrm{~min}$. It indicates that the performance of the HPLC system gave a good performance for the quantitative analysis of domperidone.

\section{Selectivity}

The proposed method was selective for the analyte and the internal standards. There were no significant interference chromatograms between endogenous compounds from blank plasma and domperidone or propranolol $\mathrm{HCl}$ at a retention time of about 6-9 min, where both peaks appeared. The good separation of those peaks was confirmed by chromatograms of blank plasma and plasma spiked with domperidone, and the internal standard is shown in Fig. 1. The resolution of domperidone and propranolol $\mathrm{HCl}$ was about 8.30. Therefore, the method showed good selectivity.

\section{Linearity}

The linearity of the method was obtained by linear regression analysis to calculate intercept, slope, correlation coefficient. The linear regression equation and correlation coefficient are presented in Table 2. The percentage recovery results met the requirements, i.e., $\pm 20 \%$ for LLOQ and $\pm 15 \%$ for other concentrations from the nominal value. The method also showed quite linear within the concentration range with an $r$-value of more than 0.99 [23].

\section{Accuracy and precision}

The results of accuracy and precision are presented in Table 3. It exhibited that $\%$ error at all levels of accuracy
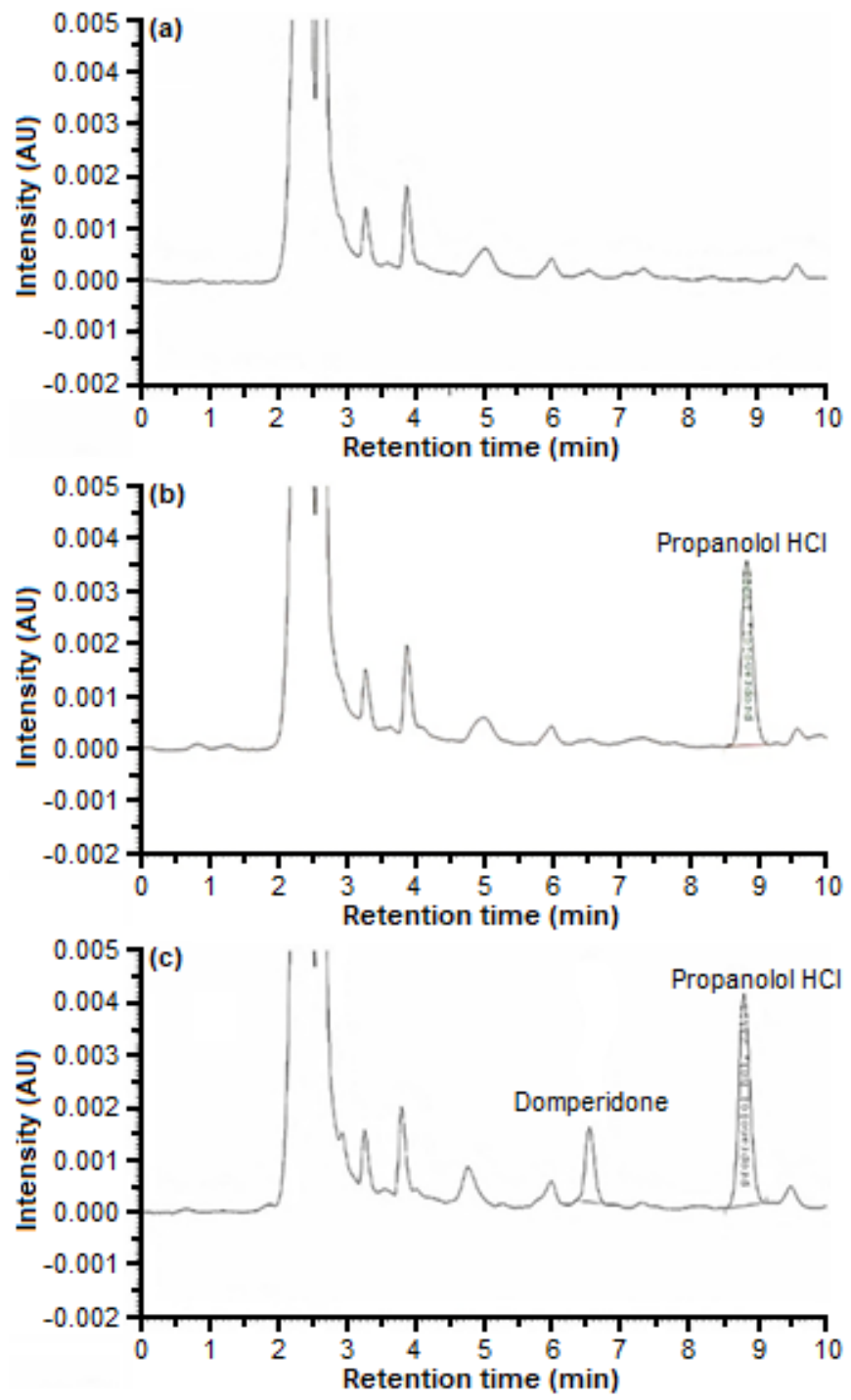

Fig 1. Chromatogram of blank plasma (a), blank plasma spiked with internal standard (b), and blank plasma spiked with domperidone and internal standard (c) with phosphate buffer:acetonitrile (70:30, v/v) as mobile phase

Table 1. System suitability test

\begin{tabular}{llrcrc}
\hline \multirow{2}{*}{ Parameters } & \multirow{2}{*}{ Requirement } & \multicolumn{2}{c}{ Domperidone } & \multicolumn{2}{c}{ Propranolol HCl } \\
\cline { 3 - 6 } & & Mean $^{*}$ & CV $(\%)$ & Mean $^{*}$ & CV (\%) \\
\hline Peak area (AU) & $\mathrm{CV} \leq 2 \%$ & 6433.50 & 1.18 & 22706 & 1.06 \\
Retention time (min) & $\mathrm{CV} \leq 2 \%$ & 6.57 & 0.47 & 8.83 & 0.46 \\
Asymmetry & $\leq 2$ & 1.10 & 2.75 & 1.16 & 0.89 \\
$\begin{array}{l}\text { Resolution } \\
\text { Height equivalent to the }\end{array}$ & $>2$ & 8.30 & 0.23 & 8.30 & 0.23 \\
theoretical plate (HETP) & $>2000$ & \multirow{2}{*}{11393.83} & \multirow{2}{*}{1.43} & \multirow{2}{*}{14000.83} & 0.68 \\
\hline
\end{tabular}

${ }^{*}$ Data were mean of six times injection repetition 
Table 2. Linear regression data for the calibration curve and sensitivity of the method

\begin{tabular}{ll}
\hline Parameters & Values \\
\hline Range (ng/mL) & $15-200$ \\
Linear regression equation & $\mathrm{y}=0.0015 \mathrm{x}+0.0119$ \\
Correlation coefficient & 0.998 \\
Lower limit of quantification (LLOQ) & $15 \mathrm{ng} / \mathrm{mL}$ \\
\hline
\end{tabular}

both within-run and between-run were not exceeded $15 \%$, except for LLOQ not exceeding 20\%. Meanwhile, the precision study showed by $\%$ CV values were $<15 \%$ and LLOQ $<20 \%$. These parameters satisfied the standard guideline acceptance criteria.

\section{Lower limit of quantification (LLOQ)}

The LLOQ value of this study was $15 \mathrm{ng} / \mathrm{mL}$. The concentration value showed \% error recovery and precision was $<20 \%$ and \% recovery in the range of 80 $120 \%$. Those parameters indicate that the concentration was fulfilled the requirements of the standard guideline.

In this article, the comparison between the proposed method and previous reports was presented in Table 4 . From Table 4, it can be indicated that the proposed method had some advantages. Compared with a previous report [7], which used solid-phase extraction (SPE) in sample preparation, the proposed method used a simple extraction method, which was protein precipitation by using only acetonitrile as deproteination agent and also had better sensitivity. In addition, the process analysis in the instrument is faster than the previous report, which needed more than $10 \mathrm{~min}$ [3]. These studies showed the proposed method had good, acceptable parameters validation responses and no needed a long time in preparation sample and separation time in the instrument. Regarding the method in this study was conducted in vitro, further research is necessarily performed, such as applying this method directly in pharmacokinetic studies in animals or humans.

\section{- CONCLUSION}

The HPLC method from the study (in vitro) was simple, rapid, and accurate. The method showed good selectivity, linearity, sensitivity, accuracy, and precision. Thus, the proposed method could be the reference for the quantification of domperidone in the plasma sample.

\section{- ACKNOWLEDGMENTS}

The research work was funded by The Ministry of Research, Technology, and Higher Education of the Republic of Indonesia through the program Pendidikan Magister menuju Doktor untuk Sarjana Unggul (PMDSU) scheme.

\section{- AUTHOR CONTRIBUTIONS}

Sekar Ayu Pawestri conducted the experiment and wrote the manuscript. Akhmad Kharis Nugroho, Endang Lukitaningsih, Purwantiningsih prepared and revised the manuscript. All authors agreed to the final version of this manuscript.

Table 3. Accuracy and precision of the method

\begin{tabular}{lrrrrrr}
\hline The nominal concentration of & \multicolumn{3}{c}{ Within-Run $(\mathrm{n}=5)$} & \multicolumn{3}{c}{ Between-Run $(\mathrm{n}=10)$} \\
\cline { 2 - 7 } domperidone in spiked plasma $(\mathrm{ng} / \mathrm{mL})$ & Mean & Error $(\%)$ & CV $(\%)$ & Mean & Error $(\%)$ & CV $(\%)$ \\
\hline 15.015 & 15.42 & 2.72 & 14.24 & 15.66 & 4.31 & 13.15 \\
45.045 & 44.86 & -0.40 & 12.72 & 44.00 & -2.31 & 9.85 \\
95.095 & 87.02 & -8.49 & 9.41 & 90.61 & -4.72 & 9.94 \\
150.150 & 140.35 & -6.52 & 7.17 & 141.75 & -5.60 & 5.11 \\
\hline
\end{tabular}

Table 4. The comparison between the proposed method and the other method using reversed phase-HPLC-UV

\begin{tabular}{llll}
\hline Parameter & Method $A^{*}$ & Method B [3] & Method C [7] \\
\hline Linearity & $\mathrm{r}=0.998$ & $\mathrm{r}=0.997$ & N/A \\
Range $(\mathrm{ng} / \mathrm{mL})$ & $15-200$ & $10-600$ & N/A \\
Sensitivity & LLOQ $=15 \mathrm{ng} / \mathrm{mL}$ & LLOQ $=10 \mathrm{ng} / \mathrm{mL}$ & LOD $=1 \mu \mathrm{g} / \mathrm{mL}$ \\
Extraction method & Protein Precipitation & Protein Precipitation & Solid Phase Extraction \\
\hline${ }^{*}$ method A= the proposed method & &
\end{tabular}




\section{- REFERENCES}

[1] Athukuri, B.L., and Neerati, P., 2017, Enhanced oral bioavailability of domperidone with piperine in male Wistar rats: Involvement of CYP3A1 and P-gp inhibition, J. Pharm. Pharm. Sci., 20, 28-37.

[2] Helmy, S.A., and El Bedaiwy, H.M., 2014, Pharmacokinetics and comparative bioavailability of domperidone suspension and tablet formulations in healthy adult subjects, Clin. Pharmacol. Drug Dev., 3 (2), 126-131.

[3] Khan, A., Iqbal, Z., Khadra, I., Ahmad, L., Khan, A., Khan, M.I., Ullah, Z., and Ismail, 2016, Simultaneous determination of domperidone and Itopride in pharmaceuticals and human plasma using RPHPLC/UV detection: Method development, validation and application of the method in in-vivo evaluation of fast dispersible tablets, J. Pharm. Biomed. Anal., 121, 6-12.

[4] Yamamoto, K., Hagino, M., Kotaki, H., and Iga, T., 1998, Quantitative determination of domperidone in rat plasma by high-performance liquid chromatography with fluorescence detection, $J$. Chromatogr. B: Biomed. Sci. Appl., 720 (1-2), 251255.

[5] Bayyari, M.A., Tutunji, L.F., Al-Bayyari, N.S., and Tutunji, M.F., 2015, Liquid chromatography tandem mass spectrometry method for determination of domperidone in human plasma, J. Chem. Pharm. Res., 7 (1), 980-985.

[6] Smit, M.J., Sutherland, F.C.W., Hundt, H.K.L., Swart, K.J., Hundt, A.F., and Els, J., 2002, Rapid and sensitive liquid chromatography-tandem mass spectrometry method for the quantitation of domperidone in human plasma, J. Chromatogr. A, 949 (1-2), 65-70.

[7] Ali, I., Gupta, V.K., Singh, P., and Negi, U., 2014, SPE-HPLC techniques for separation and identification of domperidone in human plasma, $J$. Liq. Chromatogr. Relat. Technol., 37 (18), 2587-2597.

[8] Abdul, M.I.M., Siddique, S., Ur Rahman, S.A., Lateef, D., Dan, S., and Bose A., 2018, Simple bioanalytical method development and validation of micronised domperidone $20 \mathrm{mg}$ tablets using LCMS-MS and its pharmacokinetic application in healthy Indian volunteers, Afr. J. Pharm. Pharmacol., 12 (27), 416420.

[9] Wu, Y., Chu, Y., Zhang, Y., Wu, D., and Gu, J., 2007, Liquid chromatography-electrospray quadrupole linear ion trap mass spectrometric method for quantitation of domperidone in Chinese healthy volunteers, Chem. Res. Chin. Univ., 23 (4), 408-411.

[10] Bose, A., Bhaumik, U., Ghosh, A., Chatterjee, B., Chakrabarty, U.S., Sarkar, A.K., and Pal, T.K., 2009, LC-MS simultaneous determination of itopride hydrochloride and domperidone in human plasma, Chromatographia, 69 (11), 1233-1241.

[11] Abbas, G., Saadullah, M., Rasul, A., Shah, S., Khan, S.M., Hanif, M., and Ahmed, M.M., 2020, Development and validation of high-performance liquid chromatography method for the simultaneous monitoring of pantoprazole sodium sesquihydrate and domperidone maleate in plasma and its application to pharmacokinetic study, Acta Chromatogr., 32 (3), 157-165.

[12] Yoshizato, T., Tsutsumi, K., Kotegawa, T., Imai, H., and Nakano, S., 2014, Determination of domperidone in human plasma using high performance liquid chromatography with fluorescence detection for clinical application, $J$. Chromatogr. B, 961, 86-90.

[13] Qiu, X.J., Zheng, S.L., Wang, Y.F., Wang, R., and Ye, L., 2014, Rapid and sensitive UPLC-MS/MS method for the determination of domperidone in human plasma and its application to pharmacokinetic study, Drug Res., 64 (6), 330-334.

[14] Wang, X., Qin, F., Jing, L., Zhu, Q., Li, F., and Xiong, Z., 2012, Development and validation of UPLC-MS/MS method for determination of domperidone in human plasma and its pharmacokinetic application: UPLC-MS/MS method for determination of domperidone in human plasma, Biomed. Chromatogr., 27 (3), 371-376.

[15] Palem, C.R., Goda, S., Dudhipala, N.R., and Yamsani, M.R., 2016, Development of ultra fast liquid chromatography (UFLC) method for 
fluorescence detection of domperidone in human serum and application to pharmacokinetic study, Am. J. Anal. Chem., 7, 12-21.

[16] Zhang, D., Chen, K., Teng, Y., Zhang, J., Liu, S., Wei, C., Wang, B., Liu, X., Yuan, G., Zhang, R., and Guo, R., 2012, Determination of domperidone in human plasma using liquid chromatography coupled to tandem mass spectrometry and its pharmacokinetic study, Arzneimittelforschung, 62 (3), 128-133.

[17] Purba, N.B.R., Rohman, A., and Martono, S., 2019. Validation and application of reversed-phase highperformance liquid chromatography for quantitative analysis of Acid Orange 7 and Sudan II in blusher products, J. Appl. Pharm. Sci., 9 (7), 100-105.

[18] EMA, 2011, Guideline on Bioanalytical Method Validation, European Medicines Agency, London, United Kingdom.

[19] Kohler, I., Schappler, J., and Rudaz, S., 2013, Microextraction techniques combined with capillary electrophoresis in bioanalysis, Anal. Bioanal. Chem., 405 (1), 125-141.

[20] Lakshmana, S., and Suriyaprakash, T.N.K., 2012, "Extraction of drug from the biological matrix: A review" in Applied Biological Engineering, Eds. Naik, G.R., InTechOpen, Rijeka, Croatia, 479-506.

[21] Wiraagni, I.A., Mohd, M.A., bin Abd Rashid, R., and bin Mohamad Haron, D.E., 2019, Validation of a simple extraction procedure for bisphenol A identification from human plasma, PLoS One, 14 (10), e0221774.

[22] Veigure, R., Lossmann, K., Hecht, M., Parman, E., Born, R., Leito, I., Herodes, K., and Kipper, K., 2020, Retention of acidic and basic analytes in reversed phase column using fluorinated and novel eluent additives for liquid chromatography-tandem mass spectrometry, J. Chromatogr. A, 1613, 460667.

[23] Notario, D., Martono, S., Ikawati, Z., Hakim, A.R., Jannah, F., and Lukitaningsih, E., 2017, A rapid and simple high-performance liquid chromatographic method for determination of levofloxacin in human plasma, Indones. J. Chem., 17 (1), 54-62.

[24] Wei, X., Pang, Z., Fan, G., Xu, X., and Wang, L., 2018, Simultaneous prediction of retention times and peak shapes of sulfonamides in reversed-phase high-performance liquid chromatography, Trans. Tianjin Univ., 24 (3), 256-262. 